\title{
PENGONTROLAN ALAT PENCAMPUR TEH MENGGUNAKAN ANDROID BERBASIS BLUETOOTH
}

\author{
Ahmad mungalim ${ }^{1}$ \\ e-mail: ahmad.mungalim@raharja.info
}

\begin{abstract}
Introduction Technology bluetooth is many use for sector elektronika. Application for system introduction bluetooth is many in tool technology (example handphone) and a market commercial, handphone or smartphone that operation system android can donwload in playstore that can be install in handphone android. Essence smartphone this moment be an smartphone multyfunction can do service internet (WAP, GPRS, 3G, 4G) and have operation system self can do a use as control tool operasion system open souce have google. That give name ANDROID as control tools long distance (remot) its a use net bluetooth for control tools mixing tea. Method that make a software that a can aktive be software that already install in handphone that use operation system android. Hardware equipped with module bluetooth HC-05 that use for communicated between hardware and software. Data to send for net bluetooth to mikrokontroler Atmega328P. Microcontroler play role as brain for device hardware. A between smartphone and device hardware eachs do pairing device to be able connected until between can communication.
\end{abstract}

Keywords: Android, Atmega328p, Bluetooth HC-05, Smartphone

\begin{abstract}
ABSTRAK
Teknologi pengenalan bluetooth sudah banyak digunakan dalam bidang elektronika. Aplikasi dari sistem pengenalan bluetooth banyak di integrasikan pada peralatan teknologi (contohnya telephone seluler) dan di pasarkan secara komersial, sebuah perangkat handphone atau smartphone yang sistem operasinya android bisa mendowload di playstore yang bisa di instal di hp android. Esensi smartphone saat ini merupakan smartphone multifungsi yang mampu menggunakan layanan internet (WAP, GPRS,3G, 4G) dan memiliki sistem operasi tersendiri yang mampu di gunakan sebagai alat pengontrolan sistem operasi open souce milik google. Yang diberi nama ANDROID sebagai pengontrolan alat jarak jauh (remot) dengan memanfatkan jaringan bluetooth untuk mengontrol alat pencampur teh. caranya dengan membuat sebuah hardware yang dapat diaktifkan oleh software yang sudah diinstal di handphone yang menggunakan sistem operasi android. Hardware dilengkapi dengan mmodul bluetooth HC-05 yang digunakan untuk jalur komunikasi antara hardware dan software. Data dikirim melalui jaringan bluetooth ke mikrokontroler Atmega328P.mikrokontroler berperan sebagai otak bagi device hardware. Antara smartphone dan device hardware masing masing melakukan pairing device untuk dapat terhubung sehingga keduanya dapat saling komunikasi
\end{abstract}

Kata Kunci : Android, Atmega328p, Bluetooth HC-05, Smartphone 


\section{PENDAHULUAN}

Seiring dengan berkembangnya dunia industri dan teknologi mengenai robot pada zaman sekarang ini, peranan smartphone sebagai media kontrol untuk penunjang dalam mempermudah penggunaanya semakin hari semakin besar dan berkembang, pengontrolan robot yang menggunakan media smartphone telah menghasilkan berbagai kemudahan yang bisa meringankan pekerjaan manusia. terutama dalam pengontrolan alat-alat industri yang banyak di temui diperusahaan- perusahaan pada saat ini.

Seiring dengan pesatnya teknologi di dunia industri, dan masih banyaknya perusahaan- perusahaan yang menggunakan peralatan - peralatan secara konvensional ,sebagaimana untuk mematikan atau pun menghidupkan mesin industri operator harus mendatangi panel yang berisi alat kendali penuh. Sistem control otomatis dengan perintah Bluetooth pada alat pencampur teh ini dapat mempermudah dan mempersingkat waktu manusia dalam menjalankan pekerjaanya, juga dapat meningkatkan keamanan, di mana mobilitas manusia semakin tinggi dan ketepatan waktu menjadi faktor utama yang sangat diperlukan pada zaman tekhnologi saat ini. Untuk itu dibutuhkan suatu alat otomatis yang dapat mengontrol dan menggerakkan suatu mesin secara otomatis dengan cepat dan aman.Agar dapat menambah efisiensi waktu.

\section{PERMASALAHAN}

Berdasarkan hasil wawancara yang dilakukan pada PT CS2 POLA SEHAT, sistem yang berkerja saat ini masih manual. Manual disini diartikan bahwa user harus bergerak lebih ekstra untuk mengerjakan sesuatu hal yang bisa dikerjakan dengan mudah tanpa harus bekerja ekstra. Dapat diambil satu masalah yang mempengaruhi kegiatan dalam mematikan arus listrik dari stokkontak
Dihadapia itu user bisa saja tersetrum karna adanya kebocoran arus listrik dari stop kontak tersebut.

1. yang mungkin pernah dialami oleh stakeholder. Setelah

mengamati dan meneliti dari beberapa permasalahan yang terjadi pada sistem yang berjalan, terdapat beberapa permasalahan yang dihadapi, antara lain: Sistem pengontrolan peralatan pencampur teh masih manual.

2. User bisa saja lupa untuk mematikan peralatan baling - baling atau pun pompa transfer (karena jauh dari stop kontak).

\section{LITERATUR RIVIEW}

Penelitian yang telah dijalankan oleh Ahmad Mungalim yang berjudul "Pengontrolan Alat Pencampur Teh Menggunakan Bluetooth dan mikrokontroler ATmega328P pada PT CS2 POLA SEHAT",

Sistem ini dibuat untuk memperbaiki sistem yang masih menggunakan sistem konvensional pada alat industri, dimana masih banyak peralatan yang digerakkan oleh lebih dari satu orang dalam pelaksanaan kerja alatnya.

Dan sistem yang akan diusulkan pada penelitian ini memanfaatkan mikrokontroler dan teknologi Modul bluetooth yang saat ini masih belum banyak yang menggunakan.Untuk membantu para generasi muda dalam mengembangkan suatu sistem alat otomatis, dengan memanfaatkan mikrokontroler sebagai alat embedded yang sangat cerdas dan fleksibel untuk mengontrol berbagai macam alat elektronik dan mesin industri. 
Banyak penelitian yang sebelumnya dilakukan mengenai memanfaatkan mikrokontroler dan teknologi sensor bluetooth yang saat ini masih belum banyak yang menggunakan. literature review sebagai salah satu dari penerapan metode penelitian yang akan dilakukan. Diantaranya yaitu:

1. Penelitian yang dilakukan oleh Herdian.[2015] dengan judul : PROTOTYPE ROBOT PENYIRAM TANAMAN MENGGUNAKAN SMARTPHONE ANDROID BERBASIS ARDUINO PADA KELURAHAN DS. SUKA ASIH KEC. PASAR KEMIS KAB. TANGERANG penelitian ini memiliki tujuan untuk memudahkan Memberikan kemudahan dalam penyiraman tanaman, dan Mengimplementasikan sebuah system control robot penyiram tanaman menggunakan Bluetooth yang berbasis mikrokontroller ATmega2560 sehingga pekerjaan penyiraman di KELURAHAN DS. SUKA ASIH KEC. PASAR KEMIS KAB. TANGERANG akan sangat terbantu karena robot ini.

2. Penelitian yang dilakukan oleh Meidy Surya Hadi Putra.[2014] dengan judul : HOME SMART AUTOMATIC

$\begin{array}{lr}\text { MENGGUNAKAN } & \text { MEDIA } \\ \text { BLUETOOTH } & \text { BERBASIS } \\ \text { MIKROKONTROLLER }\end{array}$

ATMEGA 328 penelitian ini memiliki tujuan untuk membantu rutinitas dalam kehidupan sehari hari, menciptakan suatu sistem pengontrolan peralatan rumah yang berguna bagi masyarakat dan mampu berjalan dengan mudah serta dapat membantu meringankan seseorang dalam pengontrolan peralatan.
3. Penelitian yang dilakukan oleh Yuni Haryati.[2014] dengan judul : PROTOTIPE ROBOT PEMBERSIH LANTAI BERBASIS ARDUINO UNO MENGGUNAKAN SMARTPHONE ANDROID PADA PERGURUAN TINGGI RAHARJA. Penelitian ini memiliki tujuan Mempermudah dalam melakukan pekerjaan rumah khususnya membersihkan lantai dan Mengganti pekerjaan manusia dengan prototype robot pembersih lantai.

4. Penelitian yang dilakukan Septiyan Madza Zaman pada tahun (2013). Dari Perguruan Tinggi Raharja

5. yang berjudul PENGGONTROLAN PERALATAN RUMAH TANGGA MENGGUNAKAN BLUETOOTH DAN MIKROKONTROLLER

AT89S2051. pada penelitian ini pengontrolan menggunakan mikrokontroller AT89S2051. untuk menggontrol benda atau objek menggunakan media bluetooth.

6. Peneltian yang dilakukan Barnas Hardianto pada tahun (2015). Dari perguruan Tinggi Raharja yang berjudul SISTEM KONTROL KURSI RODA MENGGUNAKAN ARDUINO MEGA $2560 \quad$ PADA PUSKESMAS SUKAWALI. Pada penelitian ini pengontrolan menggunakan mikrokontroller ARDUINO MEGA 2560. Untuk mengontrol benda atau objek menggunakan media bluetooth.

\section{PEMECAHAN MASALAH}

Setelah mengamati dan meneliti dari beberapa permasalahan yang terjadi pada sistem yang berjalan, terdapat 
beberapa alternatif pemecahan dari permasalahan yang dihadapi, antara lain:

1. Membuat alat kontrol untuk mengatur peralatan tersebut.

2. Membuat simulasi perancangan tersebut untuk diberikan kepada user melalui prototipe.

\section{IMPLEMENTASI}

Implementasi dari penguraian diatas adalah dengan membuat sistem pengontrolan alat pencampur teh menggunakan android berbasis bluetooth, penanganan kekurangan dalam penggunaan saklar manual dimana setiap mengoprasikan alat user harus ketempat panel utama yang lokasinya berjauhan dengan tanki pencampur.

Hasil akhir yang ingin di capai bukan hanya pengontrolan alat pencampur teh yang dikontrol menggunakan android via bluetooth saja, tetapi pengontrolan teh automatis menggunakan android dengan meminimalisir peran dari user. Maka diterapkanlah alat di bawah ini.

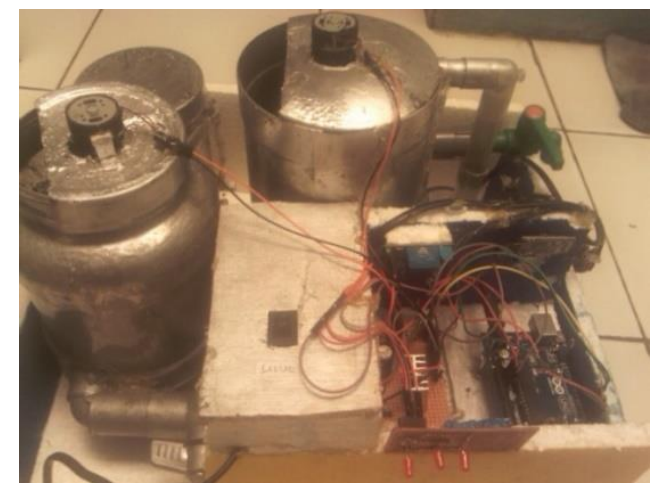

Gambar 1.Alat Pencampur Teh

Pada gambar 1 diatas merupakan alat pencampur teh menggunakan android berbasis bluetooth. Dalam hal tersebut dapat diketahui bahwa modul bluetooth menerima data dan data tersebut di keluarkan dalam bentuk led dimana led tersebut dijadikan acuan bahwa pompa dan baling-baling menyala.

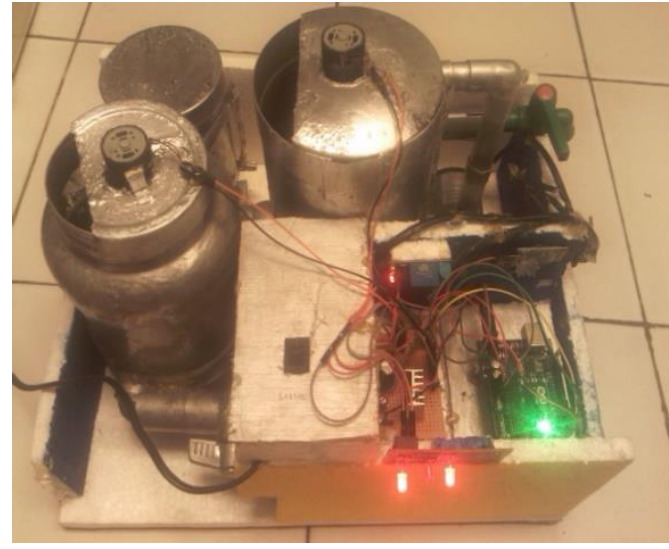

Gambar 2.Lampu Led Menyala

Gambar diatas menunjukan bahwa alat bekerja sesuai perintah user dan lain halnya dengan gambar 3 yang menunjukan alat tidak sedang beroperasi sebagaimana perintah user

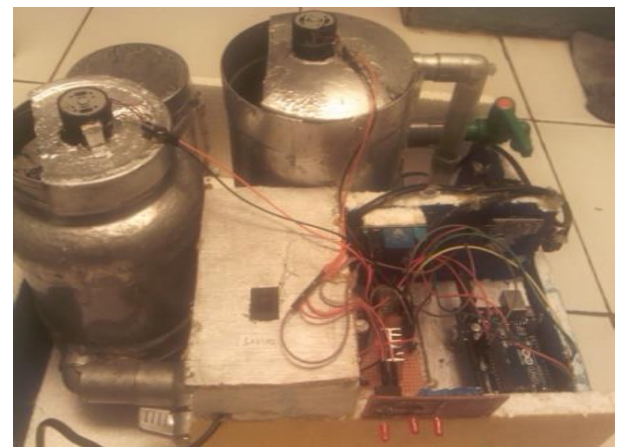

Gambar 3.Lampu Led Mati

Blok Diagram alat pencampur teh menggunakan android berbasis bluetooth

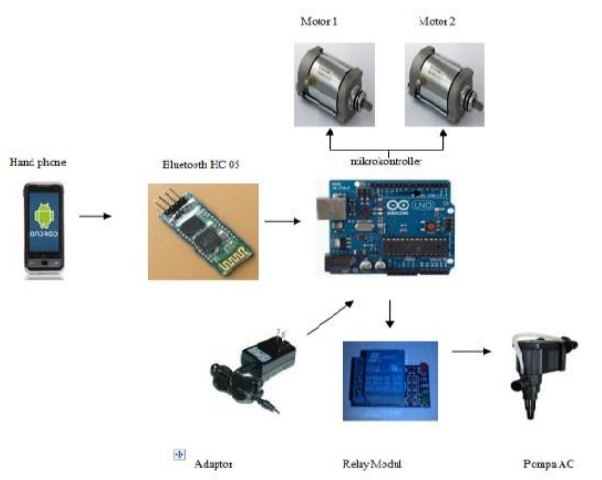

Gambar 4. Blok Diagram Alat Pencampur Teh 


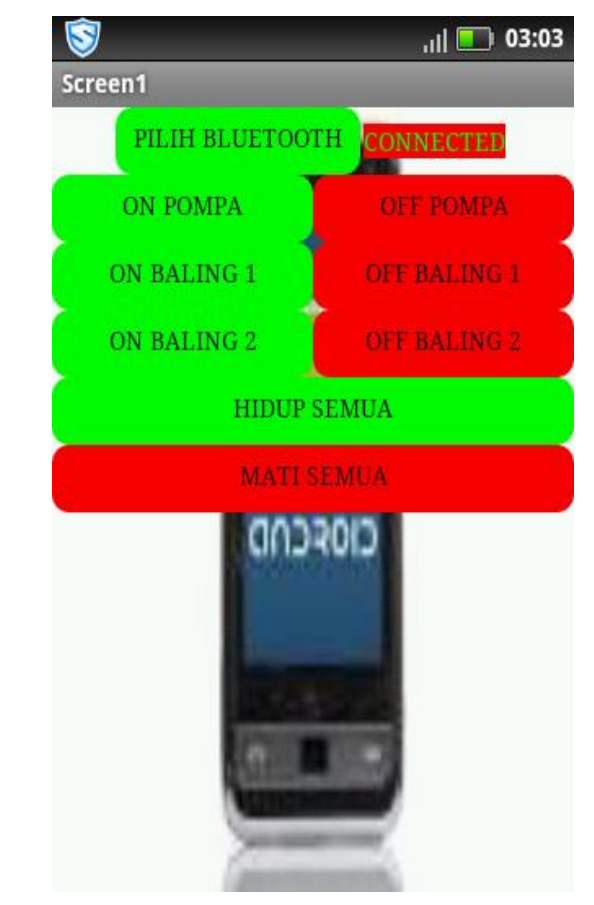

Gambar 5. Aplikasi Pencampur Teh

Flow chart sistem kerja alat pencampur teh menggunakan android berbasis bluetooth

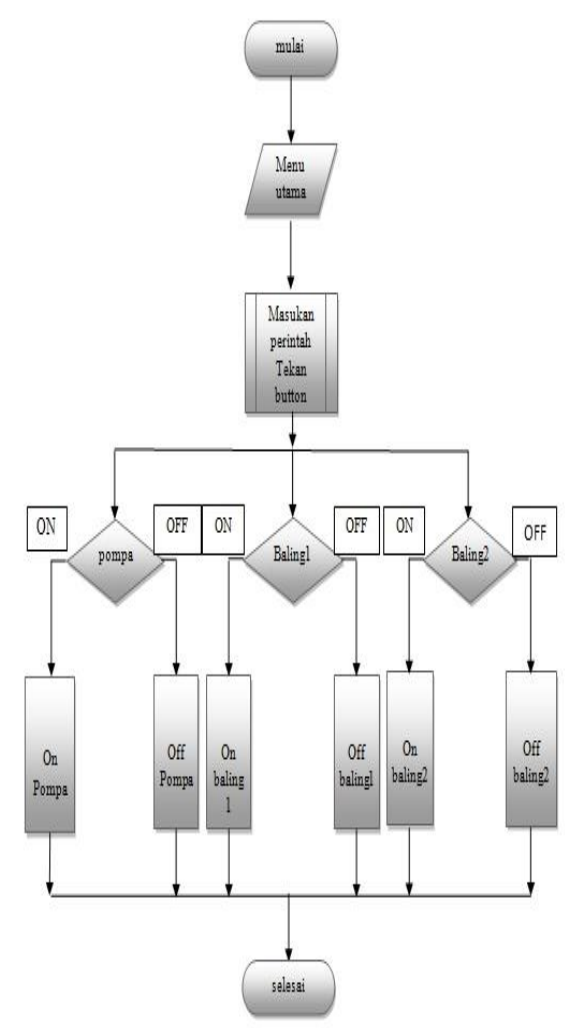

Gambar 6. Flowchart Cara Kerja Alat
Listing program

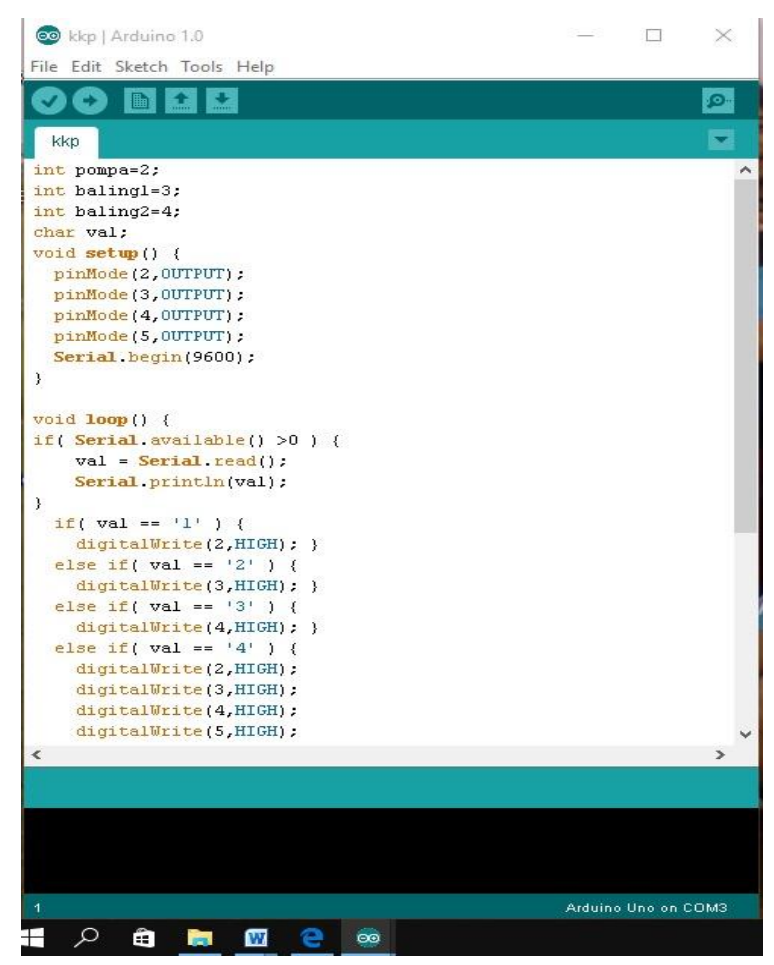

Gambar 7. Listing Program

Dari kondisi yang terjadi sesuai denagn gambar diatas, maka dapat disimpulakan bahwa alat akan menyala bila user menekan comond button sesuai dengan sesuai kebutuhan user.

\section{KESIMPULAN}

Alat pencampur teh menggunakan android berbasis bluetooth mengunakan output pompa AC dan baling-baling merupakan bagian penting dalam industri makanan dan minuman. Cara kerja alat pencampur teh menggunakan android berbasis bluetooth sangat membantu dalam proses produksi di industri. Alat ini sangat membantu user dalam melaksanakan aktivitas tanpa harus mendekati panel utama dalam pengoprasian alat pencampur teh dan juga agar user terhindar dari sengatan listrik apabila panel utama mengalami hubung singkat. 


\section{DAFTAR PUSTAKA}

1. Herdian, "Prototype Robot Penyiram Tanaman Menggunakan Smartphone Android Berbasis Arduino Pada Kelurahan Ds. Suka Asih Kec. Pasar Kemis Kab. Tangerang" Jurusan Sistem Komputer, Skripsi, Tangerang : Raharja. 2015

2. Saputra. Riyan "Pengontrolan Peralatan Rumah Dengan Menggunakan Mikrokontroller AT89S51 Dan Remote Inframerah" Jurusan Sistem Komputer, Skripsi,Tangerang: Raharja. 2015

3. H. barnas. "Sistem kontrol kursi roda menggunakan Arduino Mega 2560 Pada Puskesmas Sukawali" Jurusan Sistem Komputer, Skripsi, Tangerang : Raharja. 2015

4. Kodir. Abdul. 2015. Buku Pintar Pemrograman Arduino. jakarta: Mediakom.

5. Munir. Rinaldi. 2011. Algoritma \& Pemrograman Dalam Bahasa Pascal dan C. bandung: Informatika.

6. Ageng Setiani Rafika, Sudaryono, dan Wisnu Dwi Andoyo (2015). "Prototype Perancangan Sistem Otomatis Pembaca Suhu Ruangan Menggunakan Output Kipas Dan Sensor Lm35 Berbasis Mikrokontroler Atmega 16" Jurnal CCIT Vol.8 No.2 Januari 2015.Tangerang: Perguruan Tinggi Raharja.

7. Ageng Setiani Rafika, Meidy Surya Hadi Putra, Winda Larasati (2015). "Smart Home Automatic Menggunakan Media Bluetooth Berbasis Mikrokontroller Atmega 328" Jurnal CCIT Vol.8 No.3 Mei 2015. Tangerang: Perguruan Tinggi Raharja 